Technological University Dublin

DÜBLIN

ARROW@TU Dublin

2005-01-01

\title{
Putting Supply Chain Learning Theory into Practice: Lessons from an Irish Case
}

\author{
Edward Sweeney \\ Technological University Dublin, edward.sweeney@tudublin.ie \\ Pietro Evangelista \\ Institute for Service Industry Research (IRAT) \\ Renato Passaro \\ University of Naples
}

Follow this and additional works at: https://arrow.tudublin.ie/nitlart

Part of the Business Administration, Management, and Operations Commons

\section{Recommended Citation \\ Sweeney, E., Evangelista, P. \& Passaro, R. (2005) Putting Supply Chain Learning Theory into Practice: lessons from an Irish case. International Journal of Knowledge and Learning, Vol. 1, No. 4, pp. 357-372.}

This Article is brought to you for free and open access by the National Institute for Transport and Logistics at ARROW@TU Dublin. It has been accepted for inclusion in Articles by an authorized administrator of ARROW@TU Dublin. For more information, please contact arrow.admin@tudublin.ie, aisling.coyne@tudublin.ie, gerard.connolly@tudublin.ie.

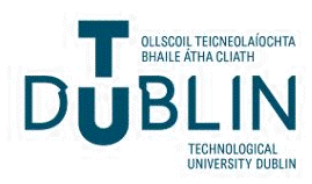




\title{
Putting supply chain learning theory into practice: lessons from an Irish case
}

\author{
Edward Sweeney ${ }^{\mathrm{a}}$ \\ National Institute for Transport and Logistics (NITL) \\ Dublin Institute of Technology (DIT) \\ Pietro Evangelista ${ }^{\mathrm{b}}$ \\ Institute for Service Industry Research (IRAT) \\ National Research Council (CNR) \\ Renato Passaro ${ }^{\mathrm{C}}$ \\ Institute of Business Studies \\ University of Naples Parthenope
}

\begin{abstract}
The logistics service market is currently going through a fundamental transition. The development of closer relationships with customers and the continuous adaptation of products and services, represent potentially successful approaches to the development of improved competitive capability. To this end knowledge resources and learning processes increasingly represent key elements within the evolving framework of the 3PL business. This paper describes the case of NITL's Foundation Certificate Programme (FCP) learning programme with specific reference to its use in addressing some of current shortcomings related to supply chain knowledge and skills in the Irish third party logistics (3PL) industry. The FCP rationale is based on the need to move from traditional approaches of supply chain organisation where the various links in the chain were measured and managed in isolation from each other and thus tended to operate at cross purposes, towards more integrated approaches.
\end{abstract}

Keywords: Supply Chain Learning, Third Party Logistics Service Providers Industry, Training and Education, Case Study

\footnotetext{
${ }^{a}$ E. Sweeney, Director of Learning, National Institute for Transport and Logistics (NITL), Dublin Institute of Technology (DIT), 17 Herbert Street, Dublin 2, Ireland, Tel. +353 1 6445711, Fax +353 1 6611943, E-mail: Edward.Sweeney@nitl.ie

${ }^{b}$ P. Evangelista, Researcher in Logistics and Transport at the Institute for Service Industry Research (IRAT), National Research Council (CNR), via M. Schipa, 115 - 80122 Naples, Italy; Tel. +39 0812470920 , Fax +39 081 2470933; email: p.evangelista@irat.cnr.it (corresponding author)

${ }^{c}$ R. Passaro, Professor of Business Economics at the Institute of Business Studies, University of Naples Parthenope, Via Medina, 40 - 80133 Naples, Italy; Tel. +39 081 5474729; Fax +39 081 5522313; email: rpassaro@usa.net
} 


\section{Introduction}

Supply chain management (SCM) is concerned with the strategic management of those activities which together provide customers with the appropriate level of service at optimum cost. Recent years have seen significant changes in the nature and the role of SCM. This is a result of increasingly discerning customers, more sophisticated marketplaces and shortening product lifecycles. Furthermore, the trend towards outsourcing of supply chain functionality has resulted in the creation of more virtual supply chain architectures (Clarke, 1998; Crowley, 1998). This, combined with globalisation of markets for product and service inputs, as well as for finished products, has led to supply chain planning and execution becoming more complex than ever. In addition, advanced information and communications technology (ICT) tools are now playing a critical role in enabling integration of processes both within and between companies (McDonnell, Sweeney, 2001).

As a result of these changes SCM has moved up the value hierarchy and has shifted from a largely labour intensive orientation to a more knowledge intensive one. This has profound implications for learning needs in all supply chain companies (Hyland et al., 2001; Hult, et al., 2002). In recent years companies generally, and manufacturing companies specifically, have tended to concentrate on those activities which are regarded as core competencies. The corollary of this is that many activities regarded as being non-core have been outsourced (Razzaque, Sheng, 1998; McKinnon, 1999). Third party logistics service providers (3PLs) have been well placed to benefit from this trend and have in many cases increased the scope and range of their activities. The net result of this is that many 3PLs, which were purely transportation providers in the past, now offer a range a value-adding supply chain services such as warehousing, inventory management, contract manufacturing and supply chain integration. In addition, the competitive scenario in the 3PL market has become much more complex as a result of the dissemination of ICT and web technologies that have spurred the entry of new players from unexpected industries (Regan, Song, 2001; Evangelista, 2002). This has serious implications in terms of knowledge and skill requirements (Evangelista, Sweeney, 2003). However, the 3PL sector has not traditionally had a strong culture of training and education. (Morvillo, 2002). This situation needs to be addressed if the sector is to achieve its true competitive potential in the coming years.

The National Institute for Transport and Logistics (NITL) in Ireland was established by the Irish government in 1998 to support companies in Ireland in improving their logistics and SCM capability. It provides a range of services to companies, including 3PLs, all of which are aimed at building better capability in the increasingly challenging market environment. One innovative supply chain learning programme offered by NITL is the Foundation Certificate Programme (FCP). This programme is aimed as existing or emerging supervisory and middle managers, and owner-managers of small 3PLs, who have extensive practical 
experience of one or more aspects of the supply chain but who do not necessarily hold formal academic or professional qualifications. The programme develops participants through modules in all key aspects of SCM, namely: customer service; purchasing management; production planning and control; transport and distribution management; and, warehousing and inventory management. In addition, there is an introductory module and a concluding module which is concerned with the use of ICT as a supply chain integration enabler. Since 1999, over 100 participants have registered for the programme many of whom are from the 3PL sector. 3PL companies in Ireland have used the programme as a primary mechanism for developing the supply chain learning required in the evolving business environment.

This paper describes how many of the current shortcomings in relation to SCM learning in 3PLs can be addressed using the FCP. Following this introduction, the paper discusses the issues of knowledge management, learning processes and relational learning in general terms to set the context and theoretical framework for the subsequent analysis. The application of these theories to SCM in general, and to 3PLs learning requirements specifically, is discussed in the following section. The critical issue of the role of ICT as a supply chain enabler is given specific focus. The paper then goes on to describe NITL's FCP in detail, with specific reference to its use in addressing some of current shortcomings in 3PL learning. In essence, the action research methodology is adopted to assess to role of initiatives such as FCP in bridging the gap which is currently evident between learning theory and 3PL reality. Following a discussion of the pertinent issues, a number of concluding comments and observations are made.

\section{Knowledge management, learning processes and relational learning}

\subsection{Knowledge management and learning processes}

Knowledge is a composite resource whose development occurs over time through processes of accumulation and renewal based on the capacity to manage information resources, human resources (HR) and ICT tools. Information is a critical element of knowledge. However, it differs greatly from the latter as it is identified with evidence or data and, in the traditional sense, it leads to a more rational use of material resources. By contrast, knowledge has a creative element lacking in information. Information may be said to have a content of objectivity, while knowledge mainly depends on human resources (whether individuals, social groups or organisations), their mental models, their capacity to interact and measure up to other actors according to the objectives to be attained (Boisot, 1998). Thus knowledge is not a homogeneous resource, but rather consists of different components related to the level of knowledge accumulated, firms' strategies, reaction capacity to changes, and the competence of human resources (Lundvall, 1992). 
The capacity to manage and develop knowledge, in its various forms, has become an increasingly important determinant of competitive advantage and value creation, making companies undertake major investments in knowledge management (KM) so as to possess a resource which has progressively become strategic. $\mathrm{KM}^{1}$ arises from the growing importance that knowledge resources have assumed in underpinning firm competitiveness following major processes of technological and organisational innovation that have progressively limited the significance of material resources and traditional space-time barriers. This course of action may be pursued in several ways: mergers, acquisition of firms or firm's department, employment of skilled human resources, $R \& D$, HR development, co-operative initiatives with external actors who possess complementary knowledge.

The key role that HR play (whether individuals, social groups or members of an organisation) in developing knowledge is shown in the learning processes that fuel the flow of information processing and knowledge accumulation. A view of learning consistent with a composite view of knowledge considers both the capacities and tools that reflect skills, knowhow, and conceptual capacities (know-why) which highlight the ability to interpret experience and set up new cognitive principles (Kim, 1993).

Individual learning represents the growth of the ability of an individual to perform an action effectively. The concept of organisational learning is understood as the creation, development and transfer of new knowledge within an organisation using a dedicated organisational system able to define operational guidelines and change the behaviour of actors. The decisive factors in an organisational learning system are the cultural and organisational factors that affect the processes of sharing activities and knowledge, trust between parties, and the presence and quality of cooperative relations. The learning organisation is a system structurally arranged to support processes of growth, development and knowledge enforcement through interaction between the knowledge of individuals and that possessed by organisations to improve performance in terms of cost, time and quality (Schein, 1992; Leonard-Barton, 1992; Garvin, 1993; Narver, Slater, 1995; Grant, 1996, Easterby-Smith et al., 1999; Teece, 2000) ${ }^{2}$.

This interaction occurs operationally within organisational routines through which tacit knowledge is transformed into shared (explicit) knowledge (Nelson, Winter, 1982). This is not an automatic transition since there are both inhibiting and facilitating factors that influence the efficiency of the process (Antonacopoulou, 1999). The former can be represented both by obstacles that limit, slow down or prevent the learning of the organisation from individuals (March, Olsen, 1975) and by barriers stemming from mismatching in the shared mental model of internal groups of individuals (Kim, 1993). The latter can be observed both at individual level (willingness to learn, to identify own learning needs, errors tolerance, feedback on performance improvements, etc) and at context level 
(climate encouraging and rewarding learning, openness to change, competitive climate, integration).

Knowledge is progressively enhanced due to the interaction between knowledge residing in the various levels of the company system by individual, group, organisational and interorganisational learning processes (Nonaka, 1991). Inter-organisational learning concerns issues of knowledge development of a system of organisation tied by socio-economic relations and to this end a process of learning across organisational boundaries can be realized (Dixon, 1999). In this context, there may be impediments to learning caused by various firm-specific elements (cultures, skills, ownership structure, environmental contexts, size, etc.). By contrast, in the framework of a supply chain there are elements at work that reduce these learning impediments (for example, a co-operative climate, shared objectives and knowledge, organisational integration, mutual learning). These allow the supply chain to exploit the synergies and benefits of a corporate system (speed of adaptation, anticipation of changes, rationalisation of resources, etc.) (Christopher, 1992; National Research Council, 2000; Brewer et al., 2001).

\subsection{Relational learning}

As regards traditional economic studies, the notion of learning refers to an experiential approach based on conditions of passivity of economic actors and on conditions of stability in the reference context (Arrows, 1962). Such constraints are overcome within the evolutionary view of the concept of double loop learning which tackles the stability of the reference conditions (i.e. existing routines) and proposes a proactive learning behaviour, questioning the baggage of past knowledge to verify the tuning with a new context, trying to anticipate the process of change (Argyris, Schon, 1978; Argyris, 1992). This cognitive mechanism exploits cognitive criteria to innovate both in relation to cumulative cognitive assets and to the methods and operative tools adopted. This aims to achieve learning unhampered by the limits of the same conceptual tools and procedures adopted and hence able to generate continuous self-reinforcing processes which are required to be able to define and manage complex knowledge. Continuous self-reinforcing processes imply relational forms of learning based on the ability to co-ordinate, pro-activeness, and adaptation to requirements of partners and customers.

Relational learning processes are based on the willingness to encourage organisational integration, the search for new solutions and, in general, the decisive change for improving performance and process efficiency (learning by relating). This willingness implies the growth of one's own knowledge base by broadening knowledge relative to best operational practices, technological know-how and organisational routines (Esposito, Passaro, 1998). This willingness is stimulated and facilitated, amongst other factors, by a climate of collaborative operation and trust which develops in the presence of long-term relations, shared objectives, and the awareness that cooperation implies reciprocal strengthening 
(learning by co-operating). Collaborative know-how has been defined by Simonin (1997) as the skill in identifying, negotiating, managing, monitoring and terminating collaborations.

Participation in a network of firms allows the development of learning processes from the adaptations that each actor makes in response to changes proposed by other members in favour of efficiency and competitiveness of the whole network (learning by networking). In all these cases learning is motivated by active contact with new elements (practices, principles, solutions, etc.) which broaden cognitive horizons, and hence, competitiveness. For example, proximity to the final market and orientation to customer satisfaction, insofar as they mean the ability to take on board and/or anticipate consumer trends and their variability, constitute a learning stimulus (learning from markets) (Minguzzi, Passaro, 2000).

Contact with different environments (cultural, social, legal, etc.), as in the case of firms that enter new markets, represents a vital source of learning which may enhance one's knowledge (learning by exporting). In all such cases, a decisive factor is the firm's openness to change which promotes such contact and does not short-sightedly reject innovation (Minguzzi, Passaro, 1997).

\section{Supply chain learning and implications for the 3PL sector}

\subsection{Learning and supply chain management}

Closeness to customers, learning capacity and continuous adaptation of products and services, are essential in developing and maintaining competitive advantage. Customer closeness allows companies to develop innovation and improve growth and profitability. To this end knowledge resources and learning processes increasingly represent key elements in adapting to the changing framework of business competition (Minguzzi, Passaro, 2000).

In the SCM approach, learning has a relational nature derived from the complex system of relations linking customers to many value-added suppliers with the support of logistics service providers (Kidd et al., 2003). This issue has been considered only in recent literature. Some scholars have pointed out the concept of learning in a supply chain while others have stressed the concept of a supply chain as a learning environment. Among the former, the theoretical framework has been set for supply chain learning to support the process of innovation in logistic services. They have shown on the one hand that the SC may be a suitable learning environment as successful SCM requires firm-to-firm exchange of best practice knowledge (Flint et al., 2003); and, on the other, that leveraging the supply chain is a mechanism to enable learning and competence development (Bessant et al., 2003).

The latter stresses that learning processes are an evolutionary step in the supply chain concept that enhance the ability to learn from and respond to a changing environment through shared knowledge (Peterson, 2002). Analysis has shown that the driving factor is shared interests and interdependence between the members of the SC which allow, for example, a 
reduction in the cycle time, making the learning climate of the supply chain a strategic resource (Hult et al., 2002).

Given the importance of learning in SC efficiency, it is urgent to provide incentives for developing learning behaviour by SC participants. In other words, work needs to be undertaken on co-operative behaviour that is not restricted to mere experiential learning (learning by doing) as it does not result in the knowledge being able to work efficiently in a competitive system in which competitive rules are volatile. Mere experience arising from participation in a co-operative relation does not ensure collaborative know-how, such that future collaboration should result in greater benefits. Building collaborative knowledge should be achieved by:

- appropriate organisation and integration of human resources and ICT tools;

- appropriate organisation and renewal of firm and inter-firm routines;

- the maintenance of a tension among different types of knowledge (Lundvall, 1992).

This will allow the firm to react rapidly to change, to integrate new SCs, and to operate with greater confidence in becoming more customer-oriented and in formulating customer solutions consistent with SC efficiency. The phrase learning supply chain has also been used to describe inter-firm structures designed to promote effective knowledge and skills development throughout the supply chain (Sweeney, 2003).

In particular, for firms operating in a SCM context and with a customer-oriented approach, a learning system needs to be considered a key resource to put SC strategy into practice (Bessant et al., 2003; Hult et al., 2000; Andersen, Christensen, 2000; Flint et al., 2003). For example, in the case of 3PLs implementing a customer orientation strategy requires relational learning capabilities. For 3PLs monitoring customer requirements is critical in establishing current needs and anticipating future desires. It enables 3PLs to improve customised response and to develop related innovation in services supplied (Daugherty et al., 1992). Relational learning capabilities allow 3PLs to operate with a problem-solving approach so as to work out new organisational solutions to customer logistics needs and, at the same time, identify advanced services consistent with the objectives of customer supply chain requirements. In light of such considerations, the case of 3PLs is described in the following section.

\subsection{Supply chain learning and ICT issues in the 3PL industry}

In the last few years, a series of major changes has occurred in the logistics service industry which has profoundly changed customer-logistics provider relationships. Indeed, while the primary driving forces previously were to reduce cost and release capital for alternative purposes, the driving forces today have more strategic influences in terms of market coverage, improving the level of service or increasing flexibility towards the changing requirements of customers (Ojala, 2003). 
Relevant within this context is outsourcing which is part of the SCM concept (Lambert et al., 1998). The adoption of the SCM view has increasingly forced manufacturing and distribution companies to outsource their logistics and transportation activities as the delivery system has become an integral part of their product. The growing outsourcing of logistics activities is also consistent with the trend to reduce the number of suppliers and establish closer, long-term relationship with them.

In order to be able to serve their customers in an innovative and flexible manner, 3PLs have made many efforts to better integrate their processes throughout the supply chain, and shrink the distance between themselves and their supply chain partners. This has increased the level of supply chain integration of 3PLs improving the co-operation with customers that is often combined with changes in both organisation and information technology.

Under the technological point of view, the 3PL sector international competitive scenario in the logistics service providers industry has evolved taking into account the entry of new players spurred by the dissemination of ICT (Regan, Song, 2001). With particular reference to the impact of ICT and web technologies on the 3PL industry, three trends seem to emerge (Evangelista, 2002):

- the increasing integration of traditional services (i.e. transport and warehousing) with information services (i.e. electronic shipment tracking \& tracing, booking of space, download of cargo documentation, etc.);

- the development of new virtual intermediaries such as infomediaries or online freight e-marketplaces;

- the formation of alliances between 3PLs and other firms operating in complementary sectors, (i.e. management consulting, financial services and ICT vendors) that in some cases have given rise to the creation of a new category of service provider called Fourth Party Logistics Providers (4PLs).

Given these trends, relational learning and ICT-knowledge are key factors to better adapt 3PL organisation to the changing competitive landscape considering that, for example, the availability of capable ICT-based services is an expected dimension of 3PL service supply and is increasingly becoming a selection criteria used by customer for choosing 3PLs.

This has given 3PLs a new potential role in customising the supply chain as a growing number of activities beyond transportation and warehousing can be carried out by 3PLs (Cooper, et al., 1998) and ICT can increasing the level of customisation of the service offered (Van Hoeck, 2002; Sauvage, 2003). For example, providing solutions that include value adding services supported by ICT capabilities, such as final assembly, 3PLs can improve their competitive position (Skjoett-Larsen, 2000).

The cost of entry into the 3PL arena now includes technology and implementation capabilities for warehouse management, transportation management, and web-enabled communications. The focused efforts of 3PLs to continually upgrade and expand ICT 
capabilities have reduced many of the once differentiating high-value technologies to what are now minimum requirements. Users of 3PL services anticipate that the near-term differentiators will include electronic markets, supplier management systems, and supply chain planning. Going forward, the success of 3PLs will depend on their ability to deliver an integrated, end-to-end solution that provides significant improvements in financial and operational performance.

While today's marketplace is seeing more productive and meaningful 3PL-customer relationships evolve and customers generally report high levels of success with their 3PLs, a gap exists between what customers receive and what they expect to receive. Consequently, 3PLs need to focus on a number of key objectives, including implementing information technologies, instituting effective management and relationship processes, integrating services and technologies globally, and delivering comprehensive solutions that create value for the users and their supply chains. Considering that customer demands for performance and sophistication are accelerating, improving these areas is a key imperative for 3PLs. From this perspective business and organisational learning seem to be of critical importance for reinforcing the competitiveness of 3PLs (Evangelista, et al., 2004). Particularly in a SCM context, this implies continuous learning based on effective transfer of knowledge among supply chain partners (Bessant et al., 2003). In other words, the flexibility and agility required of companies operating in a turbulent supply chain environment can be increased through appropriate learning and training processes (Hyland et al., 2001).

\section{Case study - the Foundation Certificate Programme (FCP) in supply chain management}

\subsection{Introduction}

The National Institute for Transport and Logistics (NITL) was established in Ireland as a result of a major study commissioned by the Irish government in 1995. The report (Forfas, 1995) recognised the importance of transport, logistics and supply chain management to the continuing success of the Irish economy based on a number of factors:

- the potential economic and service benefits;

- the open nature of the Irish economy (both imports and exports represent an large proportion of economic activity and economic success depends on dynamic exportoriented firms in both the manufacturing and service sectors);

- Ireland's relative geographical peripherality;

- the changing nature of customer-supplier relationships with a strong emphasis on the development of partnership approaches; and

- developments in ICT as a key enabling technology in supply chain integration.

The report went on to recommend the establishment of "a single new national centre of excellence to support companies in improving transport, logistics and supply chain 
effectiveness”. NITL came into existence in 1998 as this centre of excellence. It achieves its mission through awareness creation activities (conferences, roadshows, magazine, etc.), the provision of support tools (self-audit packs, service directories, benchmarking clubs, etc.), delivery of consultancy services, research (both academic and applied research) and the provision of a range of innovative supply chain learning programmes.

\subsection{NITL Learning}

NITL Learning is the training and education division of NITL. It focuses on improving the supply chain capability of organisations through the delivery of a range of both in-house and open learning programmes. Currently the main programmes are as summarised in Figure 1 (below).

\section{PLACE FIGURE 1 HERE}

The range of programmes reflects the requirements of different levels of staff in organisations in all parts of the supply chain (e.g. manufacturing, logistics service provision and retail). The most recent addition to the portfolio is the Foundation Certificate Programme (FCP) which came into existence to satisfy a particular requirement and which has been adopted by several leading 3PLs in Ireland.

\subsection{Foundation Certificate Programme (FCP) - background and rationale}

The FCP was introduced in 2002 to meet a specific requirement which had become apparent to NITL in earlier years. It is aimed at existing and emerging supervisory and junior management staff, or owner-managers of small 3PLs, who have extensive experience of one or more aspects of the supply chain but who do not necessarily hold formal academic or professional qualifications. The latter is a product of the traditional lack of a training and education culture in the field, particularly within 3PLs. The structure of the programme is as shown in Figure 2 (below).

\section{PLACE FIGURE 2 HERE}

The programme aims to develop participants in all aspects of SCM based on this approach. Most participants have detailed operational knowledge of that aspect of the supply chain in which they are most experienced. However, their knowledge of other aspects of SCM is usually very limited and their view of the role of their specialist area in the context of overall supply chain performance is usually also very narrow. From the perspective of 3PLs, this specialist knowledge tends to be in the area of transport and distribution with knowledge of other supply chain areas tending to be extremely limited. The programme endeavours to 
develop participants in all aspects on the supply chain with a strong emphasis on the interaction between the constituent areas.

\subsection{Foundation Certificate Programme (FCP) - delivery and assessment}

Each programme subject is delivered as a discrete self-contained module of approximately 20 hours duration. The twenty hours is usually delivered as a block from Thursday evening to Saturday afternoon. Each module is conducted several times a year in a variety of locations in both the Republic of Ireland and Northern Ireland. Module assessment is carried out using post-module assignments (PMAs). Each PMA tests participant knowledge of the theory and concepts of the subject, as well as of the best practice models introduced during the module. Furthermore, it provides the participant with the opportunity to apply the knowledge acquired during the module in their own workplace. Submission of completed assignments usually takes place eight weeks after the module has been completed. In addition, all participants are required to complete a major in-company project towards the end of their programme of study. These projects are concerned with the analysis, planning and implementation of major supply chain change management initiatives in their organisations and are usually conducted over a three month period. While the period taken to complete the programme is deliberately kept flexible the average completion time is approximately 18 months. This involves taking modules at intervals of approximately two months. Participants who successfully complete all seven modules and the associated PMAs, and the major incompany project, are eligible for NITL's Post-Experience Certificate in Supply Chain Management. This qualification has been assessed by the UK-based Chartered Institute of Logistics and Transport (CILT) and is deemed to meet that body's educational requirements for chartered membership. 


\section{Discussion}

\subsection{FCP and relational learning}

As pointed out earlier, relational learning processes are based on the willingness to encourage organisational integration, the search for new solutions and, in general, the decisive change for improving performance and process efficiency. The FCP rationale is based on the need to move from traditional approaches of supply chain organisation where the various links in the chain were measured and managed in isolation from each other and thus tended to operate at cross purposes, towards more integrated approaches. In this way, organisational integration is not only encouraged but represents the very essence of the programme's philosophy and structure. The search for new solutions is also an important element of programme philosophy. Participants are introduced best practice during all programme modules. Assessment of modules is carried out using in-company assignments and a major in-company project. These mechanisms provide the opportunity to relate best operational practice back to participating companies. Furthermore, as the FCP is a multicompany programme, a typical module running involves participants from many parts of the supply chain (e.g. manufacturing companies, 3PLs and retail companies). This encourages the exchange of knowledge in a non-threatening and low risk environment and thus encourages improved mutual understanding and joint problem solving across the external supply chain. From a 3PL perspective specifically, staff often attend modules alongside staff from their customer companies. This has several benefits, particularly in facilitating better understanding of evolving customer requirements. Similarly, staff from various departments in individual companies often attend modules together. This facilitates a similar approach in relation to the internal supply chain. The cross-fertilisation encouraged by these mechanisms ensures that learning in achieved not only by relating but also by co-operation, by networking and from customers.

\subsection{FCP in the 3PL sector}

The FCP is particularly relevant to the learning needs of the evolving 3PL sector for a variety of reasons. Firstly, management within the sector increasingly needs to be knowledgeable in relation to a range of supply chain concepts and methodologies. In most cases it is no longer sufficient to have detailed knowledge in relation to specific transport and distribution issues. The scope of the 3PL sector has expanded. This in turn requires that the breadth of knowledge of managers at all levels in the sector expands accordingly. Customer companies are increasingly seeking to work with “one-stop shop” 3PLs which provide complete supply chain solutions and not just limited transportation services. In this environment the breadth of knowledge provided by the FCP is becoming not only desirable but essential. 
Secondly, and as pointed out earlier, the interaction between participants from companies in different parts of the supply chain promotes the cross-fertilisation of thinking. This can be particularly beneficial to participants from 3PL companies as it helps to foster a better understanding of evolving customer requirements and challenges. In the current environment of increasingly competitive and sophisticated markets, more discerning customers and shortening product life cycles this learning can be invaluable.

Finally, several design features have been incorporated into the programme to facilitate the learning process for busy managers in the 3PL sector and in particular for ownermanagers in small 3PLs. These are based on well established generic paradigms of lifelong learning. For example, participants attend modules at their own pace and not according to pre-set rigid schedules. In addition, modules are generally conducted at weekends thus avoiding serious disruption to the busy schedules of participants. As a result of the traditional lack of a learning culture in the 3PL sector, for many participants registration on the FCP is their first foray into education for many years and can be quite a daunting prospect. With this in mind, NITL provides extensive support to participants in terms of the development of appropriate learning skills.

\subsection{FCP in developing ICT knowledge}

The FCP has a strong focus on ICT as a key enabler of supply chain integration. The introductory module addresses this issue very strongly. Each of the five functional modules outlines the role of ICT in the specific areas using examples of "point" solutions to illustrate key learning points. The focus of the final module ("IT in the Supply Chain") is on integration. At this point in the learning cycle participants have been exposed to detailed knowledge concerning the specific elements of the supply chain and it is important that the central message of integration is reinforced. This final module does exactly that. The theme of the module concerns the role of ICT as a key enabler of supply chain integration. Participants are introduced to a range of SCM ICT applications, as well as to best practice in devising and implementing ICT strategies for the supply chain. In all cases there is a strong emphasis on the need to move away from the traditional approaches which were very often characterised by fragmentation towards approaches which are characterised by integration. Within 3PLs this has become a key issue in terms of ability to provide integrated supply chain solutions to customers in a range of sectors. Another issue which represents an important part of this module is the effective use of supply chain information in supporting the elimination of waste and non-value adding activities (NVAs). An NVA is any activity which adds cost or time to supply chain processes without necessarily adding value from a customer perspective. For example, the carrying of excessive levels of inventory is a common form of waste in supply chains. Inventory reduction depends on the ability of a supply chain to control inventory. Inventory control is, in turn, dependent on inventory visibility. ICT 
represents an opportunity to improve the level of inventory visibility across the supply chain, thus improving the chances of success in terms of inventory reduction.

\section{Conclusion}

The need to serve customers in an innovative and flexible manner is putting 3PLs under pressure to continuously refocus their strategies toward customers and to respond quickly to change. For 3PLs to satisfy the needs of customers, it is critical to ascertain current needs and to anticipate their future desires. This enables 3PLs to improve customised response and to develop related innovation in service supplied. To this end, knowledge resources and learning processes increasingly represent key elements to adapt to the changing framework of the business competition. Significant advantage can be gained by those companies that invest in organisational learning capabilities, knowledge bases and information systems. Developing cultures that thrive on knowledge and learning represent an effective way to gain such advantages.

The case study presented in this paper represents an interesting example of a programme that reflects the requirements of different levels of staff in organisations in all parts of the supply chain. It can be considered an effective tool in filling the SCM knowledge gap in logistics companies, particularly in the context of small and medium 3PLs. For this reason it has been adopted by several 3PLs in Ireland and its implementation appears appropriate in different countries with similar logistics market profiles.

Further research is needed to determine the impact of supply chain learning programmes on individual 3PL firm performance, as well as on the overall performance of supply chains. Nonetheless, programmes such as the FCP offer the potential to address some of the key challenges currently facing the sector.

\section{References}

Antonacopoulou E., (1999), "Developing learning managers with learning organizations: the case of three major retail banks", in Easterby-Smit et al., (1999).

Andersen P.H., Christensen P.R., (2000), "Inter-Partner Learning in Global Supply Chains: Lesson from NOVO Nordisk”, European Journal of Purchasing \& Supply Management, No. 6, pp. 105116.

Argyris C.,.Schon D.A, (1978), Organizational Learning: a Theory of Action Perspective, AddisonWesley Publishing Company, Mass.

Argyris C., (1992), On Organizational Learning, Blackwell Business, Cambridge.

Bessant J., Kaplinsky R., Lamming R., (2003), "Putting Supply Chain Learning into Practice”, International Journal of Operations \& Production Management, Vol. 23(No. 2), pp. 167-184. 
Boisot M.H., (1998), Knowledge Assets. Securing Competitive Advantage in the Information Economy, Oxford University Press, Oxford.

Brewer A.M., Button K.J., Hensher D.A., (2001), Handbook of Logistic and Supply-Chain Management, Pergamon.

Christopher M., (1992), Logistics and Supply Chain Management, Pitman Publishing, London.

Clarke P.M. (1998), "Virtual logistics. An introduction and overview of the concepts”, International Journal of Physical Distribution \& Logistics Management, Vol. 28, N. 7, pp. 486-507.

Crowley A.G. (1998), "Virtual logistics: transport in the marketspace”, International Journal of Physical Distribution \& Logistics Management, Vol. 28, N. 7, pp. 547-574.

Cooper M.C., Lambert, D.M. and Pagh J.D., (1998), “What Should Be the Transportation Provider's Role in Supply Chain Management?”, proceedings of the $8^{\text {th }}$ World Conference on Transport Research, Antwerpen University, Antwerpen, Belgium, 12-17 July.

Copacino W.C., (1998), “A growing Wave of Supply Chain Outsourcing”, Logistics Management Distribution Report, Vol. 37, No. 9.

Dixon N., (1999), Learning Across Organizational Boundaries: a Case Study of Canadian Museums, in Easterby-Smit et al., (1999).

Daugherty P.J., Sabath R.E., Rogers D.S., (eds) (1992), “Competitive Advantage Through Customer Responsiveness”, The Logistics and Transportation Review, Vol. 28 (No. 3), pp. 257-272.

Easterby-Smit M., Burgoyne J., Araujo L., (1999), Organizational Learning and the Learning Organization, Sage Publications, London.

Esposito E., Passaro R., (1998), "Logistic and Organisational Changes: the Effect on Customers/Suppliers Relationships”, International Journal of Logistics: Research and Application, Vol. 1(No. 2)., pp. 193-208.

Evangelista P., Morvillo A., Passaro R., (2004), “Innovation and Learning Processes in the Third Party Logistics Service Providers Industry”, proceedings of $13^{\text {th }}$ Annual IPSERA Conference, 4-7 April, Catania, Italy.

Evangelista P., Sweeney E., (2003), “ICT Adoption by 3PL Providers in Italy and Ireland: Towards a Learning Agenda”, proceeding of Logistics Research Network - LRN, Enhancing Global Trade through Supply Chain Solutions, Cass Business School, City University, $10^{\text {th }}-12^{\text {th }}$ September, London, UK, pp. 118-125.

Evangelista P., (2002), "Information and Communication Technology Key Factor in Logistics and Freight Transport”, In: Ferrara G. and Morvillo A. (Ed. by), Training in Logistics and Freight Transport Industry. The Experience of the European Project ADAPT-FIT, Ashgate Publishing Ltd, London, pp. 15-36.

Flint D.J, Gammelgaard B., Larsson E., (2003), “Setting the Stage for Supply Chain Learning and Logistics Innovation”, 15 ${ }^{\text {th }}$ Annual NOFOMA 2003 Conference Proceedings "Striving for Leading Edge Logistics”, Oulu, Finland, 12-13 June.

Forfas, (1995), World Class to Serve the World, Forfas, Dublin, Ireland. 
Garvin D.A., (1993), “Building a learning organization”, Harvard Business Review, July-August.

Grant R.M., (1996), "Toward a Knowledge-Based Theory of the Firm”, Strategic Management Journal, Vol.17, Special issue, winter.

Hyland P.W., Soosay C., Sloan T.R., (2001), "Continuous Improvement and Learning in the Supply Chain”, International Journal of Physical Distribution \& Logistics Management, Vol. 33, No. 4, pp. 316-335.

Hult, G.T.M., Ketchen Jr, D.J., Slater, S.F., (2002), “A Longitudinal Study of The Learning Climate and Cycle Time in Supply Chains”, Journal of Business \& Industrial Marketing, Vol. 17, No 4, pp. 302-323.

Hult G.T.M., Nichols Jr. E.L., Giunipero L.C., Hurley R.F., (2000), “Global Organizational Learning in the Supply Chain: A Low Versus High Learning Study”, Journal of International Marketing, Vol. 8, No. 3.

Kidd J., Richter F., Stumm M., (2003), "Learning and Trust in Supply Chain Management: Disintermediation, Ethics and Cultural Pressures in Brief Dynamic Alliances”, International Journal of Logistics: Research \& Applications, December, Vol. 6 (No. 4), pp. 259-275.

Kim D.H., (1993), “The Link Between Individual and Organizational Learning”, Sloan Management Review, Fall.

Lambert D.M., Cooper M.C., Pagh J.D., (1998), “Supply Chain Management: Implementation Issues and Research Opportunities”, International Journal of Logistics Management, Vol. 9, No. 2, pp. $1-20$.

Leonard-Barton D., (1992), “ The Factory as a Learning Laboratory”, Sloan Management Review, Fall.

Lundvall B., (1992), National System of Innovation: Toward a Theory of Innovation and Interactive Learning, Pinter Publishing.

McDonnell R., Sweeney E., (2001), “The role of information technology in the supply chain”, Logistics Solutions, Issue 4, pp. 9-13.

McKinnon A., (1999), “The outsourcing of logistics activities”, in Waters D. (edited by), Global Logistics and Distribution Planning, Kogan Page, London, UK.

March J.G., Olsen J.P., (1975), "The Uncertainty of the Past: Organizational Learning under Ambiguity”, European Journal of Political Research, No. 3, pp.147-171.

Minguzzi, A., Passaro R., (2000), "The Network Between the Economic Environment and the Entrepreneurial Culture in Small Firms”, Journal of Business Venturing, Vol. XVI (No. 2).

Minguzzi, A. Passaro R., (1997), «Apprentissage et Culture d'Entreprise dans les PME. Une Analyse Explorative Intersettorielle », Revue Internationale PME, No. 2.

Morvillo, A. (2002), "Trends in logistics and freight transport in Italy: implications on training needs”, in Ferrara G., Morvillo A. (edited by), Training in Logistics and Freight Transport Industry. The Experience of the European Project ADAPT-FIT, Ashgate Publishing Ltd, London, UK. 
Nonaka I., Takeuchi H., (1995), The Knowledge Creating Company, New York, Oxford University Press.

National Research Council, (2000), Surviving Supply Chain Integration: Strategies for Small Manufacturers, Committee on Supply Chain Integration, Washington DC, National Academy Press.

Nelson R., Winter S., (1982), An Evolutionary Theory of Economic Change, Belnkap Press of Harvard University, Cambridge, Mass.

Nonaka, I.,(1991), “The Knowledge-Creating Company”, Harvard Business Review, No. 69, Nov.-

Dec.

Nonaka I., Takeuchi H., (1995), The Knowledge Creating Company, New York, Oxford University Press.

Ojala, L., (2003) , “Estimating the Size of the Finnish TPL Market”, in Andersson et al. (eds.) Third Party Logistics - A Nordic Research Approach, Publication of the Turku School of Economics and Business Administration, Serie A-4, pp. 47-70.

Peterson, H.C., (2002), “The Learning Supply Chain: Pipeline or Pipedream”, American Journal of Agricultural Economics, December, Vol. 84 (No.5), p.1329.

Razzaque M.R., Sheng C.C., (1998), “Outsourcing of logistics functions: a literature survey”, International Journal of Physical Distribution \& Logistics Management Vol. 28 n. 2, pp.89-107

Regan A.C., Song J., (2001), "An Industry in Transition: Third Party Logistics in the Information Age”, paper given at the Transportation Research Board, 80 $0^{\text {th }}$ Annual Meeting, January, Washington DC, USA.

Sauvage, T., (2003), “The Relationship between Technology and Logistics Third-Party Providers”, International Journal of Physical Distribution and Logistical Management, Vol. 33, No. 3, pp. 236-253.

Schein E.H., (1992), Organizational Culture and Leadership, Jossey-Bass Publishes, S.Francisco.

Slater S.F., Narver J.C., (1995), “Market Orientation and the Learning Organization”, Journal of Marketing, July, Vol. 59 (No.3), p.63-65.

Spender J.C., (1996), Making knowledge the basis of a dynamic theory of the firm, Strategic Management Journal, December, vol. 17, p.45-62.

Skjoett-Larsen T., (2000), “TPL-from an Interorganisational Point of View”, International Journal of Physical Distribution and Logistics Management, Vol. 30 (No. 2).

Sweeney, E., (2003), "Supply chain benchmarking and performance measurement: towards the learning supply chain”, Logistics Solutions, Vol. 6, No. 6, pp.9-13.

Teece D., (2000), Strategies for managing knowledge assets: the role of firm structure and industrial context, Long Range Planning, vol.33, pp.35-54.

Van Hoeck, R., (2002), “Using Information Technology to Leverage Transport and Logistics Service Operations in the Supply Chain: an Empirical Assessment of the Interrelation Between 
Technology and Operation Management”, International Journal of Information Technology and Management, Vol. 1, No. 1, pp. 115-130.

\section{Notes}

1. KM may be defined as the set of systematic actions organised within specific strategic lines, chiefly addressing the creation of suitable organisational environments with the aid of technological systems, to acquire, enhance, create and manage knowledge (Spender, 1996; Teece, 2000).

2. In the current economic and productive contexts, an organisational system capable of learning is a sort of minimum requirement for access to the competitive arena of many sectors, whether traditional or innovative. This requires a continuous investment/commitment over time given the cumulative nature of knowledge, the great speed of the process of change requiring a reaction, which may result in the depletion of cognitive assets acquired in time, the tacit nature of much knowledge (certainly of that containing most potential) which requires appropriate economic effort and organisational solutions to achieve the broadest, swiftest economic exploitation of knowledge (Nonaka, Takeuchi, 1995). 


\begin{tabular}{|c|c|}
\hline Programme & Leading to \\
\hline Foundation Certificate Programme & Post-Experience Certificate \\
\hline SCM Development Programme & Post-Experience Cert/Diploma \\
\hline Graduate Development Programme & M.Sc. \\
\hline Fellowship Programme & M.Phil. \\
\hline Research Studies & M.Phil./Ph.D. \\
\hline In-house Learning & \multirow{3}{*}{$\begin{array}{l}\text { Certified Continuing } \\
\text { Professional Development }\end{array}$} \\
\hline Senior Executive Progr & \\
\hline Short Courses & \\
\hline
\end{tabular}

Figure 1. NITL's Supply Chain Learning Programmes

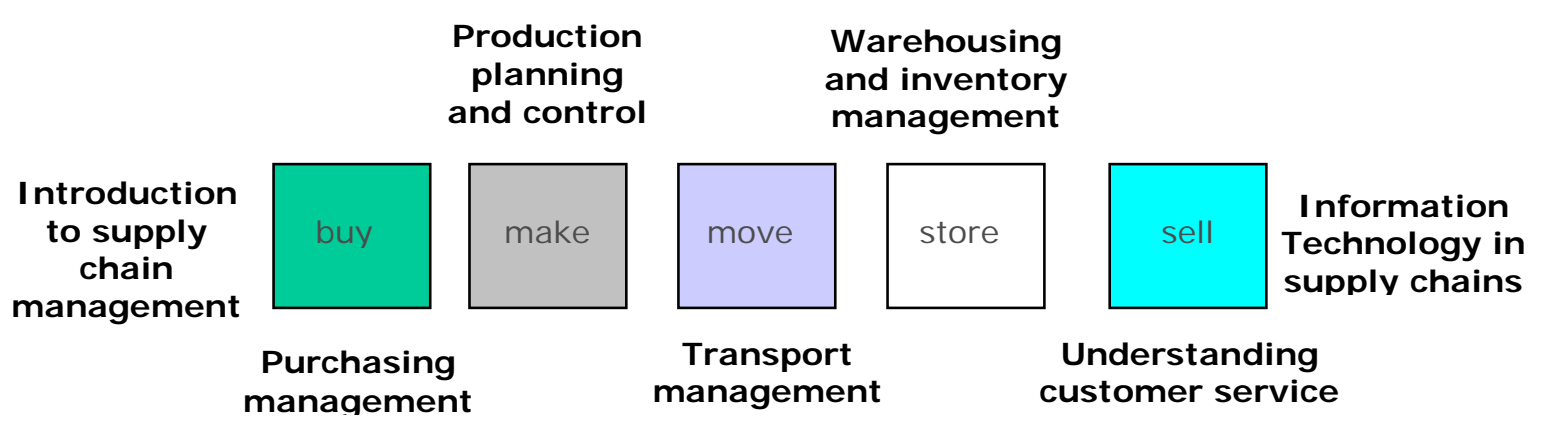

Figure 2. Structure of FCP 